\title{
Earth Observing-1 Extended Mission
}

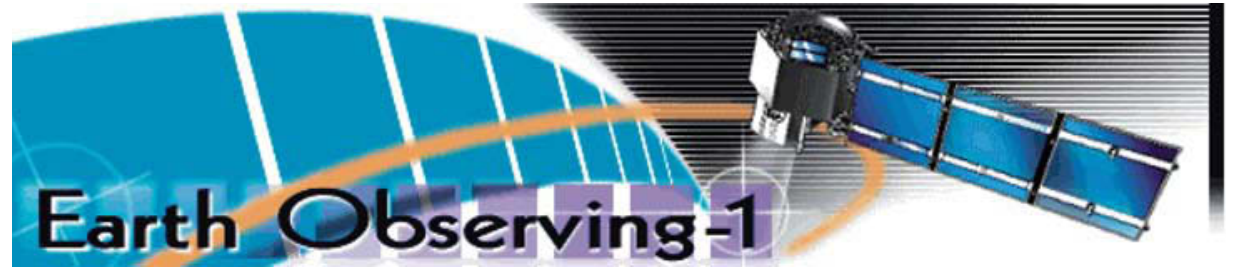

\section{Overview}

From its beginning in November 2000, the NASA Earth Observing-1 (EO-1) mission demonstrated the feasibility and performance of a dozen innovative sensor, spacecraft, and operational technologies. The 1-year mission tested a variety of technologies, some of which may be included on the planned 2007 Landsat Data Continuity Mission. Onboard the spacecraft are two land remote sensing instruments: the Advanced Land Imager (ALI), which acquires data in spectral bands and at resolutions similar to Landsat, and Hyperion, which acquires data in 220 10-nanometer-wide bands covering the visible, near-, and shortwave-infrared bands.

Recognizing the remarkable performance of the satellite's instruments and the exceptional value of the data, the U.S.
Geological Survey (USGS) and NASA agreed in December 2001 to share responsibility for operating EO-1 on a cost-reimbursable basis as long as customer sales are sufficient to recover flight and ground operations costs.

The EO-1 extended mission operates within constraints imposed by its technology-pioneering origins, but it also provides unique and valuable capabilities. The spacecraft can acquire a target scene three times in a 16-day period. The ALI instrument has additional spectral coverage and greater radiometric dynamic range compared with the sensors on Landsat 7. Hyperion is the first civilian spaceborne hyperspectral imager. As of January 2003, more than 5,000 scenes had been

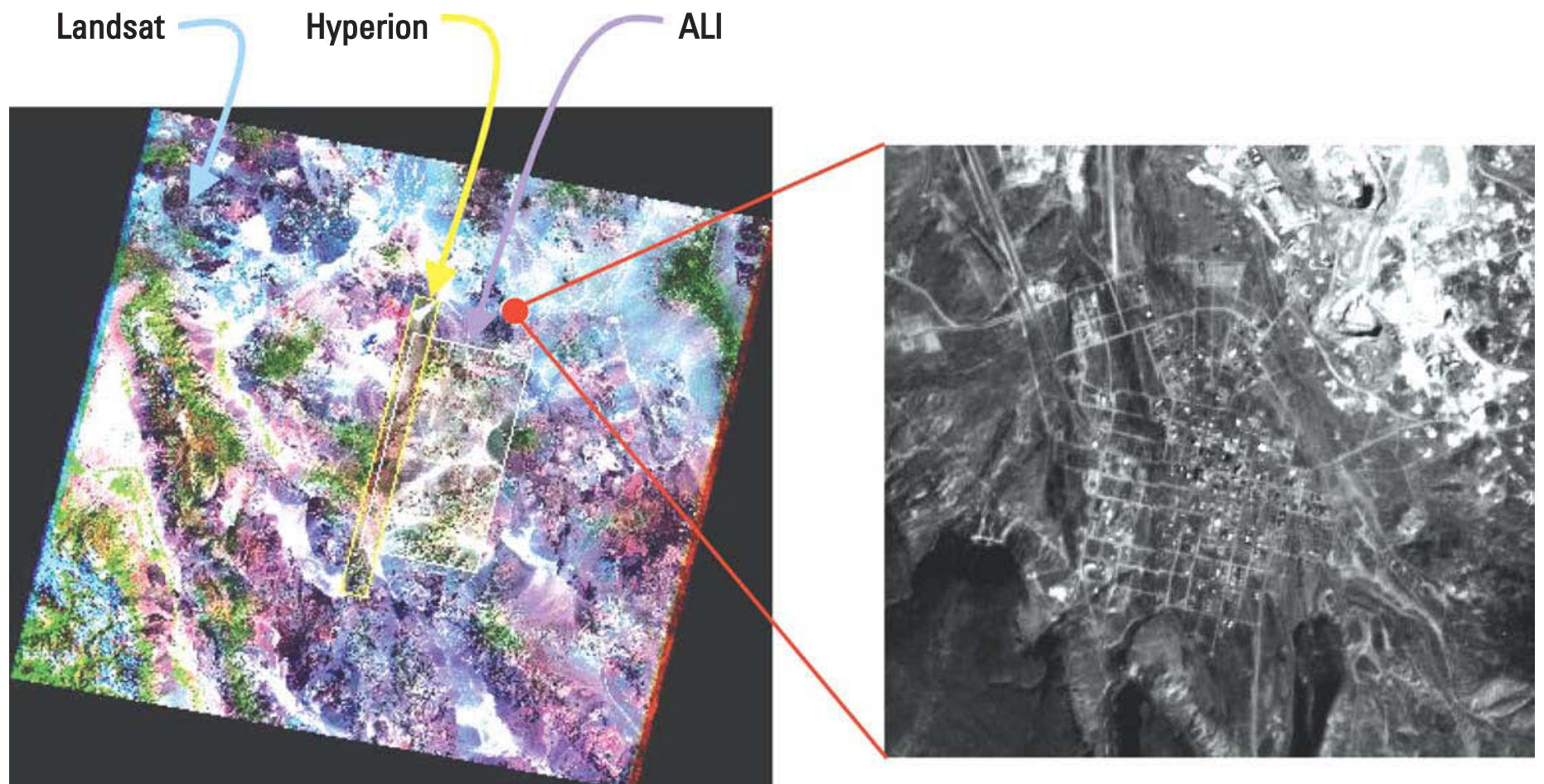

Landsat 7 image on the Nevada / California border, with ALI and Hyperion data embeded. Outlines represent the full width of the Hyperion (8- $\mathrm{km})$ and ALI (37$\mathrm{km}$ image swath.
ALI panchromatic (10-m resolution) image of Goldfield, Nevada. See red dot on composite image for location 


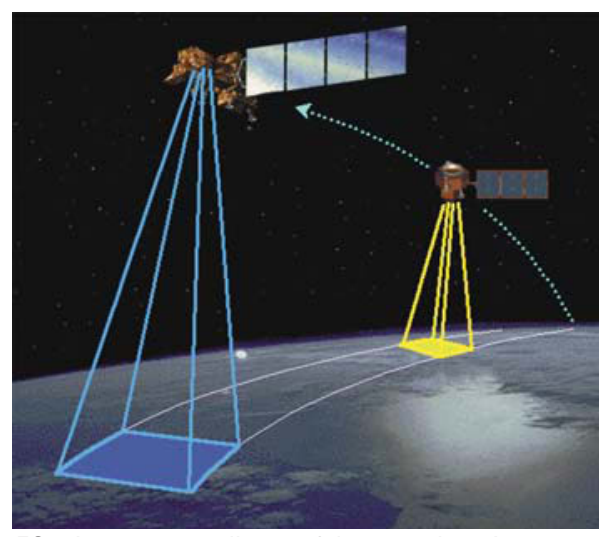

E0-1 images a small part of the same location on the ground 1 minute after Landsat 7 .

acquired, indexed, and archived.

\section{Extended Mission Roles}

NASA and the USGS are operating the EO-1 mission as efficiently as possible, using the infrastructure and operational strengths of each agency. The USGS EROS Data Center (EDC) in Sioux Falls, S. Dak., is responsible for acquisition scheduling, data reception, order processing, acquisition cataloging, archiving, and product distribution. The USGS will maintain the entire collection in its long-term archive of global land data after the satellite has been decommissioned.

The NASA Goddard Space Flight Center (GSFC) in Greenbelt, Md., manages the mission and operates the spacecraft. The GSFC coordinates data collection among the network of polar and U.S. ground stations. The GSFC also periodically adjusts the spacecraft orbit, ensuring that it follows by 1 minute along the same ground track as Landsat 7. NASA will deorbit and decommission the spacecraft at the conclusion of the mission.

\section{Extended Mission Goals}

- Sustain and enhance USGS and NASA research and development toward applications of hyperspectral and pushbroom optical scanner data within the U.S. research and operational user communities

- Promote opportunities in the remote sensing community to apply evolving imaging technology for government, scientific, and industry applications
- Provide greater insight into potential commercial developers' prototype instrument performance

- Add unique land remote sensing datasets to the USGS National Satellite Land Remote Sensing Data Archive

- Characterize long-term performance of EO-1 advanced technology sensors

\section{Applications}

USGS and NASA scientists believe both Landsat-like and hyperspectral data from EO-1 are valuable for various applications:

- Land cover studies

- Ecosystem monitoring

- Mineral and petroleum exploration

- Agricultural crop discrimination and assessment

- Environmental damage assessments

EO-1 data offer information in a wide range of bandwidths. The satellite flies in formation with Landsat 7 and builds on the technology developed by the Landsat Program. Further, EO-1 data provide a sensor and technology prototype for future space-based remote sensing missions, offering the global science community an important transition database.

\section{Data Products and Availability}

Customers are encouraged to use the USGS Web-based Earth Explorer (EE) catalog search capability to find archived scenes that lie within their geographic and temporal window. EE allows userspecified place-name and map-based searches within a given timeframe. False-color browse images allow the user to determine usability based on cloud cover.

- New acquisitions of specific locations can be ordered for $\$ 1,500$.

- Acquisitions will be retaken up to two times if assessed cloud cover over the scene exceeds 25 percent.

- Radiometrically corrected products, either from the archive or new acquisitions, may be ordered for $\$ 500$.

- Products are distributed over FTP or on CD/DVD media, typically within 7 to 10 business days for new acquisitions or 3 days if purchased from the archive.

- Products are available in HDF EOS format.

\section{Information}

To learn how to query the catalog of existing data, to order EO-1 data, or to obtain sample datasets, please go to:

eo1.usgs.gov

earthexplorer.usgs.gov

Technical information about the EO-1 mission, satellite, sensors, and science can be accessed at eo1.gsfc.nasa.gov

For information on other USGS products and services, call 1-888-ASK-USGS or visit the general interest publications Web site on mapping, geography, and related topics at erg.usgs.gov/isb/pubs/ pubslists/.

For additional information, visit the ask.usgs.gov Web site or the USGS home page at www.usgs.gov.

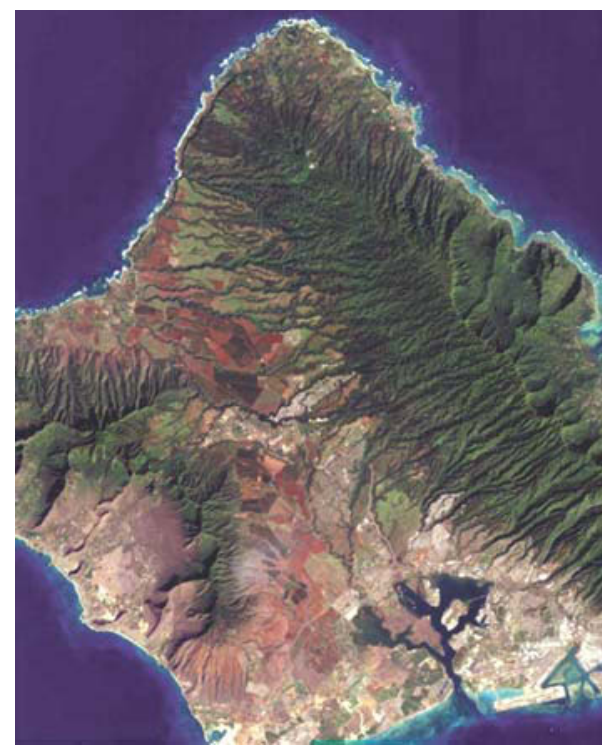

Island of Oahu, Hawaii, imaged by ALI. 